\title{
TNI Angkatan Udara dan Keamanan Wilayah Udara Indonesia
}

\author{
Rohannisa Naja Rachma Savitri*, Adya Paramita Prabandari \\ Fakultas Hukum, Universitas Diponegoro \\ *annisa.savitri@gmail.com
}

\begin{abstract}
Indonesia is a vast country and therefore has a great vulnerability in relation to its territory, especially in maintaining the security of the Indonesian airspace.There are several problems that often occur and become a nuisance in efforts to maintain the security of the Indonesian airspace, including violations of airspace including violations of airspace which requires the Indonesian Air Force to conduct identification process to destruction. Therefore, it is very interesting to analyze the role of the Indonesian Air Force in securing Indonesian airspace.The method used is normative juridical which is done by examining secondary data obtained from library studies. The data is then analyzed by qualitative methods then arranged systematically.There are still many cases of violations of national airspace that make the Air Force, especially Kohanudnas have a hard job in order to play a very vital role as a means of national defense to uphold the law and maintain national airspace security. Obstacles related to defense equipments and the authority of investigators also become a benchmark whether Indonesian airspace has been secured to the maximum or not.
\end{abstract}

\section{Keywords: Indonesian Air Force, Security, Indonesian Airspace}

\begin{abstract}
ABSTRAK
Indonesia adalah negara yang sangat luas dan oleh karenanya memiliki kerentanan kerentanan yang besar dalam hubungannya dengan teritori khususnya dalam menjaga keamanan wilayah udara Indonesia. Ada beberapa permasalahan yang kerap terjadi dan menjadi gangguan dalam upaya menjaga keamanan wilayah udara Indonesia, antara lain adanya pelanggaran wilayah udara yang mewajibkan TNI AU untuk melakukan tindakan identifikasi hingga penghancuran. Oleh karena itu, sangat menarik untuk dianalisis mengenai peran TNI Angkatan Udara dalam mengamankan wilayah udara Indonesia. Metode yang digunakan adalah yuridis normatif yang yang dilakukan dengan cara meneliti data sekunder yang diperoleh dari studi kepustakaan. Data tersebut lalu dianalisis dengan metode kualitatif kemudian disusun secara sistematis. Masih banyaknya kasus pelanggaran wilayah udara nasional membuat TNI AU, khususnya Kohanudnas memiliki pekerjaan yang berat dalam rangka menjalankan peran yang sangat vital sebagai alat pertahanan negara untuk menegakkan hukum dan menjaga keamanan wilayah udara nasional. Hambatan terkait alutsista dan kewenangan penyidik juga menjadi tolak ukur apakah pengamanan wilayah udara sudah dilaksanakan secara maksimal atau tidak.
\end{abstract}

Kata kunci: TNI AU, Pengamanan, Wilayah Udara Indonesia. 
Jurnal Pembangunan Hukum Indonesia

Volume 2, Nomor 2, Tahun 2020
Program Studi Magister Ilmu Hukum Fakultas Hukum Universitas Diponegoro

\section{A. PEndahuluan}

Negara adalah "suatu organisasi dalam suatu wilayah yang memiliki kekuasaan tertinggi yang sah dan ditaati oleh rakyatnya" (Budiardjo, 2008). Unsur pertama dari suatu negara adalah wilayah negara (yang merupakan suatu ruang yang meliputi wilayah darat, wilayah laut dan wilayah udara) dengan batasbatas tertentu yang diakui secara internasional merupakan esensi utama suatu negara (Hadiwijoyo, 2012). Dalam Konvensi Montevideo 1933 terdapat lima unsur - unsur berdirinya suatu negara yakni:

1. A permanent population (penduduk)

2. A defined territory (wilayah)

3. Government (pemerintah);

4. Capacity to enter into relations with the other states (kemampuan untuk berhubungan dengan negara lain).

Keempat unsur ini merupakan unsur konstitutif di mana unsur tersebut harus terpenuhi agar terbentuk suatu negara. Ditambah dengan unsur yang kelima merupakan unsur deklaratif di mana sifatnya adalah menyatakan, bukan unsur mutlak (jika sudah terpenuhi unsur konstitutif maka bisa tidak memerlukan unsur deklaratif).

Wilayah negara dalam konsepsi hukum internasional merupakan sentral (Arifin, 2014) bagi peneguhan eksistensi dari sebuah negara dalam menjalankan kedaulatannya. Negara Indonesia yang berdaulat mengembangkan konsep Wawasan Nusantara dengan melihat ke dalam politik kewilayahannya (Buntoro, 2014). Sebagaimana dinyatakan dalam bagian konsiderans dalam
Undang-Undang Republik Indonesia No. 43 Tahun 2008 tentang Wilayah Negara yaitu "bahwa Negara Kesatuan Republik Indonesia sebagai negara kepulauan yang berciri nusantara mempunyai kedaulatan atas wilayahnya serta memiliki hak-hak berdaulat di luar wilayah kedaulatannya dan kewenangan tertentu lainnya untuk dikelola dan dimanfaatkan sebesar-besarnya bagi kesejahteraan dan kemakmuran rakyat Indonesia sebagaimana diamanatkan dalam Undang-Undang Dasar Negara Republik Indonesia Tahun 1945", maka NKRI memiliki kedaulatan atas wilayahnya yang terdiri atas tiga dimensi, yakni dimensi wilayah darat, wilayah laut, dan wilayah udara yang merupakan satu kesatuan politis (one political unit) yang tidak dapat dipisah-pisahkan (Wiradipradja, 2009).

Wilayah NKRI terdiri dari 17.508 buah pulau yang membentang dari Sabang sampai Merauke sehingga NKRI dikenal sebagai Negara Kepulauan (yang telah mendapatkan pengakuan dengan lahirnya United Nations Convention on the Law of the Sea of 1982/UNCLOS 1982, dan telah diratifikasi dengan UU No. 17 Tahun 1985 tentang Ratifikasi United Nations Conventions on the Law of the Sea of 1982 atau Konvensi PBB tentang Hukum Laut 1982). Ribuan pulau tersebut terhubungkan oleh laut-laut dan selat-selat sehingga membentuk sebuah negara kepulauan dengan panjang $5.110 \mathrm{Km}$ dan lebar $1.888 \mathrm{Km}$, serta memiliki luas perairan 5.877.879 $\mathrm{Km}^{2}$, luas laut teritorial sekitar $297.570 \mathrm{Km}^{2}$, perairan Zona Ekonomi Eksklusif (ZEE) 695.422 km², dan panjang pantai $79.610 \mathrm{Km}$. Dua pertiga wilayah NKRI 
adalah laut, dan luas daratannya $2.001 .044 \mathrm{Km}^{2}$. Wilayah darat NKRI berbatasan dengan tiga negara tetangga (yaitu Malaysia, Papua New Guinea/PNG, dan Republik Demokratik Timor Leste/RDTL), dan di laut berbatasan dengan sepuluh negara tetangga (yaitu India, Thailand, Vietnam, Malaysia, Singapura, Filipina, Republik Palau, PNG, Australia, dan RDTL) (Hadiwijoyo, 2012). Selain wilayah darat dan wilayah laut, wilayah NKRI juga meliputi wilayah udara yang terletak di atas wilayah darat dan wilayah laut. Adapun mengenai batas ketinggian kedaulatan masing-masing negara di wilayah udara belum ada perjanjian internasional yang mengaturnya. Pada umumnya hanya disebut bahwa "berdaulat penuh atas ruang udara dan angkasa di atas wilayah teritorialnya". Apabila dilihat dari klaim-klaim dan protes yang pernah diajukan sehubungan dengan peggunaan ruang udara di atas swilayah suatu negara, maka batas paling tinggi adalah sampai garis edar Orbit Geostasioner (Geostationery Orbit), yakni kurang lebih $35.870 \mathrm{~km}$ di atas permukaan laut (Rudy, 2002).

Dengan melihat uraian fakta di atas, nampak jelas bahwa dengan wilayahnya yang sangat luas ini, Indonesia memiliki kerentanan yang besar dalam hubungannya dengan teritori (Madu dkk, 2010), khususnya dalam menjaga keamanan wilayah udara NKRI.

Ada beberapa permasalahan yang kerap terjadi dan menjadi gangguan dalam upaya menjaga keamanan wilayah udara NKRI, antara lain adanya aerial intrusion. Aerial intrusion atau pelanggaran wilayah udara adalah suatu keadaan di mana ada pesawat terbang asing yang memasuki wilayah udara suatu negara tanpa izin. Oleh karena itu, sangat menarik untuk dianalisis mengenai peran TNI Angkatan Udara dalam mengamankan wilayah udara Indonesia.

Teori yang digunakan dalam penelitian ini adalah Teori Kedaulatan Negara dan Teori Air Sovereignty. Teori Kedaulatan Negara (staatssouvereiniteit) menganggap negara sebagai "satu kesatuan idea yang paling sempurna", oleh karena itu kedaulatan berasal dari negara. Menurut George Jellineck negara adalah "die mit urspunglicher Herrscher macht ausgerüstete Verbandseinheit sesshafter Menschen" (gabungan manusia yang terorganisir di suatu daerah tertentu yang dilengkapi dengan suatu kekuasaan asli akan pemerintah) (Samidjo, 1986). Adapun menurut jenis dan sifatnya, kedaulatan dibagi menjadi kedaulatan ke dalam (interne souvereinteit) dan kedaulatan ke luar (externe souvereinteit). Kedaulatan ke dalam adalah bahwa "kekuasaan negara itu ditaati dan dapat memaksakan untuk ditaati oleh rakyatnya". Sedangkan kedaulatan ke luar adalah bahwa "kekuasaan negara itu mampu mempertahankan diri terhadap serangan yang datang dari luar dan sanggup mengadakan hubungan dengan luar negeri" (Samidjo, 1986). Berkaitan dengan kedaulatan negara di ruang negara, ada sebuah doktrin Romawi kuno yang berbunyi "cujus est solum ejus est usque ad coelum" yang berarti "barang siapa memiliki sebidang tanah maka ia memiliki segala yang berada 
Jurnal Pembangunan Hukum Indonesia

Volume 2, Nomor 2, Tahun 2020
Program Studi Magister IImu Hukum Fakultas Hukum Universitas Diponegoro di atasnya sampai ke langit dan segala yang berada di dalam tanah" (Wiradipradja, 2009). Doktrin tersebut kemudian melahirkan teori yang digunakan sebagai dasar adalah the Air Sovereignty Theory, yang menyatakan bahwa udara itu tidak bebas, sehingga negara berdaulat terhadap ruang udara di atas wilayah negaranya. Dalam konteks negara dan wilayahnya, maka negara tersebut berdaulat penuh atas ruang udara yang ada di atas wilayah darat dan laut negaranya. Hal ini telah pula diatur dalam Pasal 1 Convention on International Civil Aviation (Konvensi Chicago 1944) yakni bahwa negara memiliki kedaulatan yang complete dan exclusive atas ruang udara di atas wilayah negara tersebut. Demikian pula dalam Undang-Undang No. 1 Tahun 2009 tentang Penerbangan, khususnya dalam Pasal 5 yang menyatakan bahwa "Negara Kesatuan Republik Indonesia berdaulat penuh dan eksklusif atas wilayah udara Republik Indonesia".

Dengan demikian, karena sifat kedaulatan negara yang complete dan exclusive maka ruang udaranya tertutup bagi pesawat udara asing, dan tidak ada yang dikenal dengan sebutan hak lintas damai (rights of innocent passage) seperti di laut teritorial. Namun demikian, hal ini tidak berarti bahwa negara sama sekali menutup ruang udaranya dari penerbangan atau pesawat udara asing (Prabandari, 2019). Pesawat udara asing dapat melintas hanya dengan izin dari negara kolong. Negara kolong memiliki hak sepenuhnya untuk mengatur mengenai kedaulatan atas ruang udaranya untuk dapat dimanfaatkan bagi pertahanan negara dan sebesar- besar kemakmuran rakyat (Hughes, 1980; Wiradipradja, 2014).

Sebelum ini, telah ada beberapa penelitian yang mengangkat tema mengenai pengamanan wilayah udara terkait adanya pelanggaran wilayah udara. Ada yang membahas mengenai pelanggaran ruang udara oleh pesawat asing menurut hukum internasional dan hukum nasional Indonesia (Sefriani, 2015). Ada pula penelitian mengenai kendala hukum penindakan terhadap pesawat udara sipil asing tidak berizin yang memasuki wilayah udara Indonesia (Risdiarto, 2019). Lebih lanjut sebuah penelitian yang dilakukan oleh Vera Soemarwi membahas mengenai kedaulatan udara Indonesia dan upaya-upaya perlindungannya (Soemarwi, 2016). Lalu ada pula jurnal internasional yang membahas mengenai pelanggaran kedaulatan ruang udara Indonesia oleh pesawat asing dan sebagai negara yang berdaulat, Indonesia dapat melakukan berbagai tindakan untuk menjaga kedaulatan wilayah udara Indonesia berdasarkan hukum nasional Indonesia dan hukum internasional (Bakhtiar, Noor, \& Magassing, 2017). Selanjutnya ada pula artikel jurnal internasional yang membahas mengenai keamanan di ruang udara berdasarkan Air Defence Identification Zone (ADIZ) dalam perspektif hukum internasional (Bakhtiar dkk, 2016).

Pada penelitian ini menekankan pada peran Tentara Nasional Indonesia Angkatan Udara dalam melaksanakan pengamanan wilayah udara Indonesia dari berbagai ancaman dan gangguan dari luar. Titik fokus inilah yang membedakan penelitian ini dengan 
Jurnal Pembangunan Hukum Indonesia

Volume 2, Nomor 2, Tahun 2020
Program Studi Magister IImu Hukum Fakultas Hukum Universitas Diponegoro penelitian yang telah ada sebelumnya. Tujuan dari penelitian ini adalah untuk dapat mengetahui dan menganalisis peran TNI AU dalam melaksanakan pengamanan wilayah udara Indonesia.

\section{B. METODE PENELITIAN}

Metode pendekatan yang digunakan dalam penelitian ini adalah metode yuridis normatif yang dilakukan dengan cara meneliti data sekunder yang diperoleh dari studi kepustakaan. Data tersebut lalu dianalisis dengan metode kualitatif kemudian disusun secara sistematis.

\section{HASIL DAN PEMBAHASAN}

Pelanggaran wilayah udara (aerial intrusion) adalah suatu keadaan di mana ada pesawat terbang asing (baik sipil maupun militer) yang memasuki wilayah udara suatu negara tanpa izin (Hambali, 1994). Insiden tersebut bisa merupakan suatu kesengajaan (misalnya penerbangan gelap/black flight dengan tujuan-tujuan tertentu), maupun tanpa disengaja (misalnya pesawat tersesat/aircraft in distress).

Sepanjang tahun 2017 - 2019 masih terdapat banyak kasus pelanggaran wilayah udara nasional yang berpotensi mengancam kedaulatan NKRI. Terekam sebanyak 19 kasus pelanggaran wilayah udara yang terjadi pada tahun 2017 berupa penerbangan tanpa izin antara lain 16 kasus penerbangan yang melibatkan pesawat negara, 2 kasus yang melibatkan pesawat sipil, dan satu kasus yang tidak teridentifikasi (Fadillah, 2019). Sementara itu, selama tahun 2018, tercatat sebanyak 65 kasus melibatkan pesawat sipil, 48 kasus melibatkan pesawat negara, dan 14 kasus tidak teridentifikasi sehingga dapat dijumlahkan sebanyak 127 kasus pelanggaran yang terjadi di wilayah udara Indonesia (Halim, 2018). Lalu, sepanjang bulan Januari hingga Juni tahun 2019, sebanyak 165 kasus pelanggaran wilayah udara yang terjadi di daerah perbatasan NKRI seperti Kepulauan Riau dan wilayah perbatasan lainnya karena adanya permasalahan terkait dengan FIR Singapura (Umam, 2019).

TNI AU mempunyai peran penting dalam menyelenggarakan pertahanan kedaulatan wilayah udara NKRI dalam menghadapi ancaman keamanan di udara. Pasal 10 Undang - Undang No. 34 Tahun 2004 tentang Tentara Nasional Indonesia menegaskan bahwa tugas dari TNI AU antara lain adalah melaksanakan tugas TNI matra udara di bidang pertahanan, menegakkan hukum dan menjaga keamanan wilayah yurisdiksi nasional, melaksanakan tugas TNI dalam pengembangan matra udara, serta melakukan pemberdayaan wilayah pertahanan udara. Segala usaha untuk menciptakan kondisi wilayah udara yang aman merupakan kewajiban bagi TNI AU. Sebagai bentuk pelaksanaan tugas di atas dapat diwujudkan dalam kegiatan Operasi Militer Untuk Perang (OMP) dan Operasi Militer Selain Perang (OMSP). TNI AU merupakan kekuatan yang nyata untuk menegakkan hukum terhadap kasus pelanggaran wilayah udara sebagaimana tercantum dalam penjelasan Pasal 8 Ayat 1 Undang - Undang No.1 Tahun 2009 bahwa 
Jurnal Pembangunan Hukum Indonesia

Volume 2, Nomor 2, Tahun 2020
Program Studi Magister Ilmu Hukum Fakultas Hukum Universitas Diponegoro yang dimaksud dengan "melanggar wilayah kedaulatan Negara Kesatuan Republik Indonesia" adalah memasuki wilayah udara Indonesia tanpa izin dan tidak tertuju pada siapa yang dapat melakukan pelanggaran tersebut. Tidak hanya itu, pesawat udara yang memasuki Kawasan Udara Terlarang dan Terbatas, serta ADIZ (Air Defence Identification Zone) juga dinyatakan telah melanggar yurisdiksi negara.

Pasal 9 Undang - Undang No. 34 Tahun 2004 tentang TNI mencantumkan bahwa pihak yang berwenang untuk menindak pelanggaran wilayah yurisdiksi nasional adalah TNI AU. Bentuk upaya yang dilakukan oleh TNI AU untuk menegakkan hukum dan mempertahankan keamanan wilayah udara Indonesia yaitu dengan cara melaksanakan Operasi Pertahanan Udara dalam tahap mendeteksi, mengidentifikasi, menindak, dan menetralisir atau mengurangi dampak dari ancaman udara. Proses penindakan yang dilakukan oleh pesawat tempur TNI AU antara lain (Hakim \& Abu, 2019):

1. Shadowing (Membayang - bayangi)

Dilakukan terhadap pesawat udara yang diperkirakan akan melanggar kedaulatan wilayah udara nasional.

2. Intervention (Penghalauan)

Dilakukan terhadap pesawat udara yang melanggar wilayah udara nasional atau jalur penerbangan yang telah ditentukan/ketentuan ADIZ yang berlaku.

\section{Interception (Intersepsi)}

Peringatan yang dilakukan oleh pesawat militer TNI AU yang memasuki wilayah udara nasional tanpa memiliki izin. Intersepsi dilakukan ketika terdapat penerbangan yang tidak memenuhi persyaratan yang sudah ditetapkan dan kegiatan tersebut menggunakan pesawat udara interceptor milik TNI AU. Pelaksanaan tindakan intersepsi telah diatur dalam Pasal 32 Ayat (3) Peraturan Pemerintah No.4 Tahun 2018 yang melibatkan koordinasi antara personel pemandu lalu lintas penerbangan dengan TNI untuk pemberian informasi kepada pesawat udara TNI terkait dengan pesawat udara yang melanggar. Pelaksanaan tindakan intersepsi juga harus memperhatikan keselamatan penumpang jika pesawat yang diintersepsi adalah pesawat udara sipil. Pesawat udara yang diintersepsi juga wajib mengikuti semua perintah yang diberikan pesawat interceptor.

\section{Force Down (Pemaksaan Mendarat)}

Dilakukan terhadap setiap pesawat udara yang melanggar wilayah udara nasional dan dapat diperkirakan bermaksud untuk melakukan kegiatan kegiatan yang tidak bersahabat. Tindakan force down merupakan pemaksaan mendarat terhadap pesawat udara di Landasan Udara terdekat apabila perintah yang diberikan sebelumnya dihiraukan.

5. Destruction (Penghancuran)

Dilakukan oleh pesawat tempur sergap terhadap setiap pesawat udara yang melanggar wilayah kedaulatan dan tidak mengindahkan peringatan yang diberikan, mengancam keselamatan 
Jurnal Pembangunan Hukum Indonesia

Volume 2, Nomor 2, Tahun 2020
Program Studi Magister Ilmu Hukum Fakultas Hukum Universitas Diponegoro obyek vital, dan melakukan manuver yang membahayakan selama pesawat tempur melaksanakan penyergapan yang telah diatur dalam ROE (Rule of Engagement).

Peran TNI AU sangat penting dan krusial sebagai penjaga wilayah udara nasional agar terbebas dari ancaman keamanan kedaulatan nasional. Untuk mewujudkan peran tersebut tentu saja membutuhkan infrastruktur yang memadai. TNI AU saat ini didukung oleh 24 rada militer yang mencakup sebagian besar wilayah udara Indonesia serta memiliki delapan skadron tempur yang tersebut di berbagai kawasan di Indonesia (Roza, 2014). Akan tetapi alat utama sistem persenjataan TNI AU terdapat beberapa keterbatasan kesiapan. Hal tersebut bisa dilihat dari masih banyakanya kasus pelanggaran wilayah udara nasional yang terjadi karena kekuatan alutsista yang sudah ada tidak sebanding dengan luas wilayah yang harus dijaga sehingga faktor tersebut menjadi penghambat pengawasan wilayah udara Indonesia yang tidak dapat dilakukan secara maksimal.

Masih banyak pelanggaran wilayah udara yang terjadi dan banyak juga kasus yang tidak dapat ditangani merupakan akibat dari Alat Utama Sistem Pertahanan (Alutsista) yang terbatas dan tidak memadai di mana alutsista merupakan semua hal yang berhubungan dengan sistem senjata, kendaraan, dan perlengkapan militer lainnya yang menjadi faktor pendukung untuk pengamanan wilayah yurisdiksi nasional. Adanya penerbangan gelap yang tak mampu terdeteksi oleh radar
Komando Pertahanan Udara Nasional (Kohanudnas) dan pelanggaran udara yang tidak mampu diintersep oleh pesawat TNI AU dapat menjadi tolak ukur kelemahanan pengamanan wilayah udara nasional (Dispenau, 2019). Hal tersebut dapat menimbulkan dampak pada kedaulatan nasional dalam hal pecegahan ancaman dan gangguan dari luar. Perhatian yang lebih serius akan hal ini sangat diperlukan karena menyangkut dengan keamanan suatu negara terkhususnya pada bidang udara yang di mana untuk menjaga keamanan wilayah udara merupakan kewajiban TNI AU, namun apabila kebutuhan Alutsista (Alat Utama Sistem Persenjataan) tidak terpenuhi, patut dipertanyakan kemampuan kesiapan TNI AU dalam hal menjaga seluruh komponen bangsa Indonesia.

Melihat pentingnya tugas dari TNI AU dalam menegakkan hukum dan mengamankan wilayah udara nasional tentu saja pihak TNI AU ikut serta dalam penanganan kasus pelanggaran wilayah udara, namun keterlibatan TNI AU sampai pada proses penyelidikan kasus saja. Kewenangan penyidikan diberikan kepada PPNS (Penyidik Pegawai Negeri Sipil) Penerbangan yang berada di bawah Direktorat Jenderal Perhubungan Udara, Kementerian Perhubungan (Risdiarto, 2019). Pasal 399 Undang - Undang No. 1 Tahun 2009 tentang Penerbangan menyatakan bahwa PPNS tertentu yang lingkup tugasnya pada bidang penerbangan diberikan wewenang khusus sebagai penyidik. Penyidikan dilakukan di bawah koordinasi dan pengawasan penyidik POLRI. Hal tersebut juga 
Jurnal Pembangunan Hukum Indonesia

Volume 2, Nomor 2, Tahun 2020
Program Studi Magister Ilmu Hukum Fakultas Hukum Universitas Diponegoro menjadi salah satu faktor penghambat karena pada dasarnya, secara prosedural TNI AU yang selama ini aktif dalam penanganan kasus pelanggaran wilayah udara nasional dan sebagai pihak yang mengetahui terlebih dahulu secara rinci mengenai pelanggaran yang dilakukan oleh pesawat udara asing saat melanggar dari awal pesawat tersebut terdeteksi oleh radar sampai pada pemaksaan mendarat. Dengan itu, keterlibatan TNI AU (sebagai pihak yang berwenang untuk menegakkan hukum terkait dengan pertahanan udara) dalam proses penyidikan dinilai sangat penting agar proses penegakan hukum tidak terhambat.

Pengamanan wilayah udara secara maksimal merupakan hal yang mutlak untuk menegakkan kedaulatan di wilayah udara karena tanpa adanya pengamanan maka kedaulatan tersebut akan terancam terhadap serangan udara dari pihak luar. Oleh karena itu, TNI AU, sebagai pelaksana tugas untuk menegakkan kedaulatan wilayah udara nasional dan penegakan hukum, harus dapat terakomodir dalam segala kepentingannya agar tercapainya pengamanan wilayah udara nasional secara maksimal.

\section{SIMPULAN}

Penegakan hukum terhadap pelanggaran wilayah udara merupakan wujud dari pengamanan wilayah udara nasional yang dilakukan oleh TNI AU dengan berbagai cara yang meliputi proses identifikasi, pencegatan, pengusiran, pemaksaan mendarat, sampai pada tahap penghancuran. Tugas untuk menjaga keamanan wilayah udara nasional diamanahkan kepada TNI AU seperti yang tercantum dalam Undang - Undang No. 34 Tahun 2004 tentang TNI. Masih banyaknya kasus pelanggaran wilayah udara nasional membuat TNI AU memiliki peran yang sangat vital sebagai alat pertahanan negara untuk menegakkan hukum dan menjaga keamanan wilayah udara nasional. Di lain hal, masih terdapat juga faktor - faktor penghambat pelaksanaan pengamanan wilayah udara di antaranya terdapat pada keterbatasan alutsista sehingga pengamanan wilayah udara nasional tidak bisa terlaksanakan secara maksimal, serta perihal keterlibatan TNI AU dalam proses penyidikan pada kasus pelanggaran wilayah udara nasional yang di mana TNI AU tidak terlibat dalam proses penyidikan melainkan kewenangan tersebut hanya diberikan kepada PPNS Penerbangan sehingga proses penegakan hukum terhambat. Untuk itu, demi mengatasi hambatan di atas maka, sebaiknya TNI AU dilibatkan dalam semua proses penegakkan hukum termasuk proses penyidikan agar tercapainya kelancaran dalam penindak lanjutan terhadap pelanggar wilayah udara nasional. Pengembangan alutsista yang memadai juga diperlukan agar seluruh wilayah udara nasional dapat dijangkau oleh TNI AU sehingga dapat menjalankan tugas pengamanan wilayah udara nasional tanpa hambatan. 


\section{DAFTAR PUSTAKA}

\section{BUKU}

Arifin, S. (2014). Hukum Perbatasan Darat Antarnegara. Jakarta: Sinar Grafika.

Budiardjo, M. (2008). Dasar-Dasar IImu Politik. Edisi

Revisi Cetakan Pertama. Jakarta: PT Gramedia Pustaka Utama.

Buntoro, K. (2014). Lintas Navigasi di Nusantara Indonesia. Jakarta: PT RajaGrafindo Persada.

Hadiwijoyo, Suryo S. (2012). Aspek Hukum Wilayah Negara Indonesia. Cetakan Pertama Edisi Pertama. Yogyakarta: Graha IImu, 2012.

Hakim, Chappy., \& Abu, Supri. (2019). Penegakan Kedaulatan Negara di Udara. Jakarta: PT Kompas Media Nusantara.

Hambali, Y. (1994). Hukum dan Politik Kedirgantaraan. Jakarta: Pradnya Paramita.

Madu, L., Nugraha, Aryanta., Loy, Nikolaus., \& Fauzan. (Editor). (2010). Mengelola Perbatasan Indonesia di Dunia Tanpa Batas. Yogyakarta: Graha IImu.

Rudy, T. M. (2002). Hukum Internasional II,. Bandung: PT Refika Aditama.

Samidjo. (1986). IImu Negara. Bandung: CV. Armico.

\section{ARTIKEL J URNAL}

Bakhtiar, Handar Subhandi., Noor, Syamsuddin Muhammad., \& Magassing, Abdul Maasba. (2017). Violation of the Sovereignty of Indonesia Airspace by Foreign Aircraft. International J ournal of Advanced Research 5 , (No. 2), p. 7.
Bakhtiar, Handar Subhandi., Djanur, Nur Akifah., Ashri, Muhammad., \& Hendrapati, Marcel. (2016). Air Defense Identification Zone (ADIZ) in International Law Perspective. Journal of Law, Policy and Globalization, Vol. 56, p. 9.

Sefriani. (2015). Pelanggaran Ruang Udara oleh Pesawat Asing menurut Hukum Internasional dan Hukum Nasional Indonesia. J urnal Hukum Ius Quia lustum, Vol.22, (No. 4), p. 28.

Dispenau. (2019). Angkasa Cendekia Edisi 2019. Jakarta: Dinas Penerangan Angkatan Udara.

Hughes, William J. (1980). Aerial Intrusions by Civil Airliners and the Use of Force. J ournal of Air Law and Commerce, Vol. 45, Issue 3, pp. 595 -596 .

Prabandari, Adya P. (2019). Indonesia's Air Sovereignty Issues in the Global Era. Diponegoro Law Review, Vol.4, (No. 2), p. 13.

Risdiarto, D. (2019). Kendala Hukum Penindakan terhadap Pesawat Udara Sipil yang Tidak Berizin yang Memasuki Wilayah Udara Indonesia. J urnal Legislasi Indonesia, Vol.16, (No.3), p. 16.

Roza, R. (2014). Pengawasan Wilayah Udara Indonesia. Jurnal Info Singkat Hubungan Internasional, Vol. VI, (No.22), p. 6.

Soemarwi, Vera Wenny .S. (2016). Kedaluatan Udara Indonesia dan Upaya-Upaya Perlindungannya. Era Hukum, No. 1/TH.16/Juni 2016, p. 31.

Wiradipradja, Endang S. (2009). Wilayah Udara Negara (State Air Territory) Ditinjau dari Segi 
Jurnal Pembangunan Hukum Indonesia

Volume 2, Nomor 2, Tahun 2020
Program Studi Magister Ilmu Hukum Fakultas Hukum Universitas Diponegoro
Hukum Internasional dan Nasional Indonesia. Indonesia J ournal of International Law, Vol. 6 , (No.4), p. 396.

Wiradipradja, Endang S. (2014). The Indonesian

Sovereignty over Airspace and Its Urgency for National Economic Development. Makalah dalam 50 Years Air and Space Law Studies, Universitas Padjajaran, Bandung, 5-6 November 2014.

\section{SUMBER ONLINE}

Fadillah, R. (2020). Jejak emas TNI AU Pengawal Kedaulatan Udara Indonesia. Retrieved from https://www.merdeka.com/peristiwa/jejakemas-tni-au-pengawal-kedaulatan-udaraindonesia.html\#.

Halim, D. (2018). Sepanjang 2018 TNI AU Catat Ada 127 Kasus Pelanggaran Wilayah Udara Nasional. $\quad$ Retrieved from https://nasional.kompas.com/read/2018/12/17/ 14574831/sepanjang-2018-tni-au-catat-ada127-kasus-pelanggaran-wilayah-udaranasional.

Umam, C. (2019). KSAU Sebut Banyak Pelanggaran Terjadi terhadap Wilayah Udara Indonesia. Retrieved from https://www.tribunnews.com/nasional/2019/07/ 02/ksau-sebut-banyak-pelanggaran-terjaditerhadap-wilayah-udara-indonesia.

\section{PERATURAN PERUNDANGAN DAN KONVENSI INTERNASIONAL}

Undang-Undang Dasar Negara Republik Indonesia Tahun 1945.

Undang-Undang No. 17 Tahun 1985 tentang Ratifikasi United Nations Conventions on the Law of the Sea of 1982 atau Konvensi PBB tentang Hukum Laut 1982.

Undang-Undang No. 34 Tahun 2004 tentang Tentara Nasional Indonesia.

Undang-Undang Republik Indonesia No. 43 Tahun 2008 tentang Wilayah Negara.

Undang-Undang No. 1 Tahun 2009 tentang Penerbangan.

United Nations Convention on the Law of the Sea of 1982/UNCLOS 1982.

Convention on International Civil Aviation 1944. 